\title{
De números y más números: identificación, control y representación documental
}

1 Biblioteca Daniel Cosío Villegas, El Colegio de México. Los autores agradecen a Micaela Chávez los comentarios y observaciones al presente texto.

Números en libros; Números en tipografía; ISBN, ISSN, DOI, Clasificación bibliográfica, Números en Bibliotecas.

Numbers on

Books; Typography Numbers; ISBN, ISSN, DOI, Bibliographic Classification, Numbers on Libraries.

\author{
Numbers and more numbers: identification, \\ control and documentary representation
}

Víctor J. Cid Carmona, Claudia Escobar Vallarta ${ }^{1}$

The use of numbers in the documents, whether used as part of their content - to express quantities, formulas, measurements, positions, values, etc. - has a diverse set of applications according to defined purposes. This paper aims to give a brief description of how various numerical codes in production processes, control and identification of forms are used. To specify the type of data to which we refer, first we included a proposal of a classification about the origin of the numbers. Followed by the numbers printed in books, and then address those numbers that are noted by the owners or holders of the books. Finally, the numeric code that serves to identify documents in printed sources or online library catalogs are included.

\section{Tipificación de códigos numéricos}

Para organizar los diferentes tipos de números que se incluirán en el texto, proponemos dividirlos en tres grupos según su origen. Tomando ese principio en consideración, un primer conjunto estará integrado por números que aparecen generalmente impresos en los documentos durante el proceso de producción (internos o propios del libro), antes de salir de imprenta, o que son asignados antes de su distribución electrónica; en un segundo grupo se presentarán los casos en que los 
números son consignados manual o mecánicamente en momentos posteriores a su venta o adquisición (externos o de asignación posterior). El tercer conjunto incluye códigos numéricos que permiten la identificación de los documentos en fuentes de consulta. En conjunto, las categorías se incluyen en la tabla 1.

\begin{tabular}{|l|l|}
\hline \multicolumn{1}{|c|}{ 1. Números internos } & \multicolumn{1}{c|}{ 2. Números externos } \\
\hline Digital Object Identifier (DOI) & Clasificación \\
\hline Depósito legal & Número de autor \\
\hline Edición & $\begin{array}{l}\text { Otras anotaciones numéricas ma- } \\
\text { nuscritas }\end{array}$ \\
\hline Ejemplar & \\
\hline Página & \\
\hline Precio & \\
\hline Serie y colección & \\
\hline $\begin{array}{l}\text { Sistema Internacional de Numeración de Libros } \\
\text { (ISBN) }\end{array}$ & \\
\hline Sistema Internacional Normalizado de Series (ISSN) & \\
\hline Signatura & \\
\hline Volumen, tomo y parte & \\
\hline \multicolumn{1}{|c|}{ Representaciones del libro mediante códigos numéricos } \\
\hline Código de barras & \\
\hline Número de sistema & \\
\hline Repertorios bibliográficos & \\
\cline { 1 - 1 }
\end{tabular}

Tabla 1 Códigos numéricos en el libro

Cabe mencionar que no todos los números se utilizan de manera regular y algunos han caído en desuso, pero incluirlos nos permite ofrecer un panorama general sobre la forma en que se los ha empleado a través del tiempo. En la medida de lo posible, en la presentación de los contenidos de cada una de las categorías se seguirá un arreglo cronológico. Siempre que se consideró útil, se incluyeron además ejemplos e imágenes a fin de ilustrar el contenido.

\section{Números internos o propios del libro}

\section{Signatura}

Se trata de una de las prácticas que permite ordenar correctamente las páginas de un cuadernillo y la sucesión de éstos en un ejemplar, se coloca en el margen inferior del recto de todas las hojas del cuadernillo hasta la mitad y consiste en la utilización de la secuencia del alfabeto latino (A, B, C, D, E, F, G, H, I, K, L, M, N, O, P, Q, R, S, $\mathrm{T}, \mathrm{V}, \mathrm{X}, \mathrm{Y}, \mathrm{Z}$ ), acompañado del número de la hoja del cuadernillo en 
2 Alberto Montaner Frutos, Prontuario de bibliografía, pautas para la realización de descripciones citas y repertorios, Biblioteconomía y Administración Cultural, 34 (Gijón: Trea, 1999), 130, 138-139. números arábigos.

Según lo anterior, la sucesión de los cuadernillos A y B de un libro en octavo sería A, A2, A3, A4 (con las cuatro siguientes hojas del cuadernillo A sin signatura, figura 1), B, B2, B3, B4 (con las cuatro siguientes hojas del cuadernillo B sin signatura). Para textos muy extensos, con gran cantidad de cuadernillos, cuando se agotaba la sucesión de letras del alfabeto, se utilizaba una doble o triple mención de cada una de sus letras, la primera mayúscula y las siguientes minúsculas: Aa, Aa2, Aa3, Aa4 o Aaa, Aaa2, Aaa3, Aaa4. Como se mencionó antes, el cuadernillo de preliminares se imprimía al final y no se incluía en la secuencia alfabética, en tal caso, la signatura se

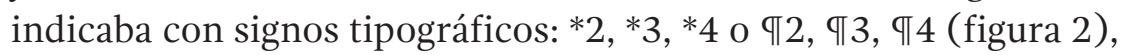
cabe advertir, que la portada no tiene signatura y en consecuencia, la signatura del cuadernillo comienza en la segunda hoja. ${ }^{2}$

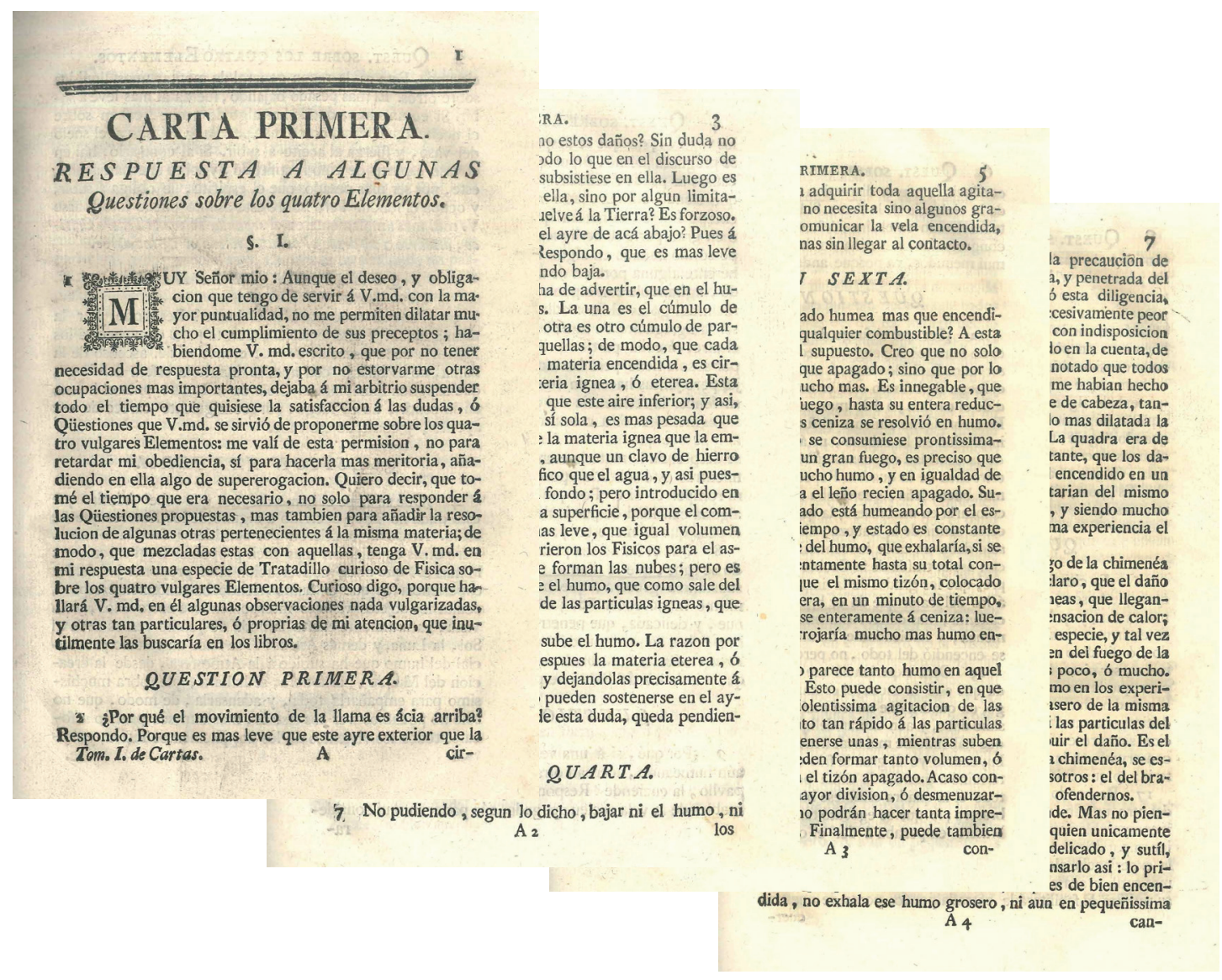

Figura 1 Indicación de la signatura del cuadernillo signado con la letra A. (Fuente: Feijoo, Benito Jerónimo. Cartas eruditas, y curiosas, en que, por la mayor parte, se continúa el designio del Teatro crítico universal ... Madrid: M. Escribano, 1774. v. 1) 


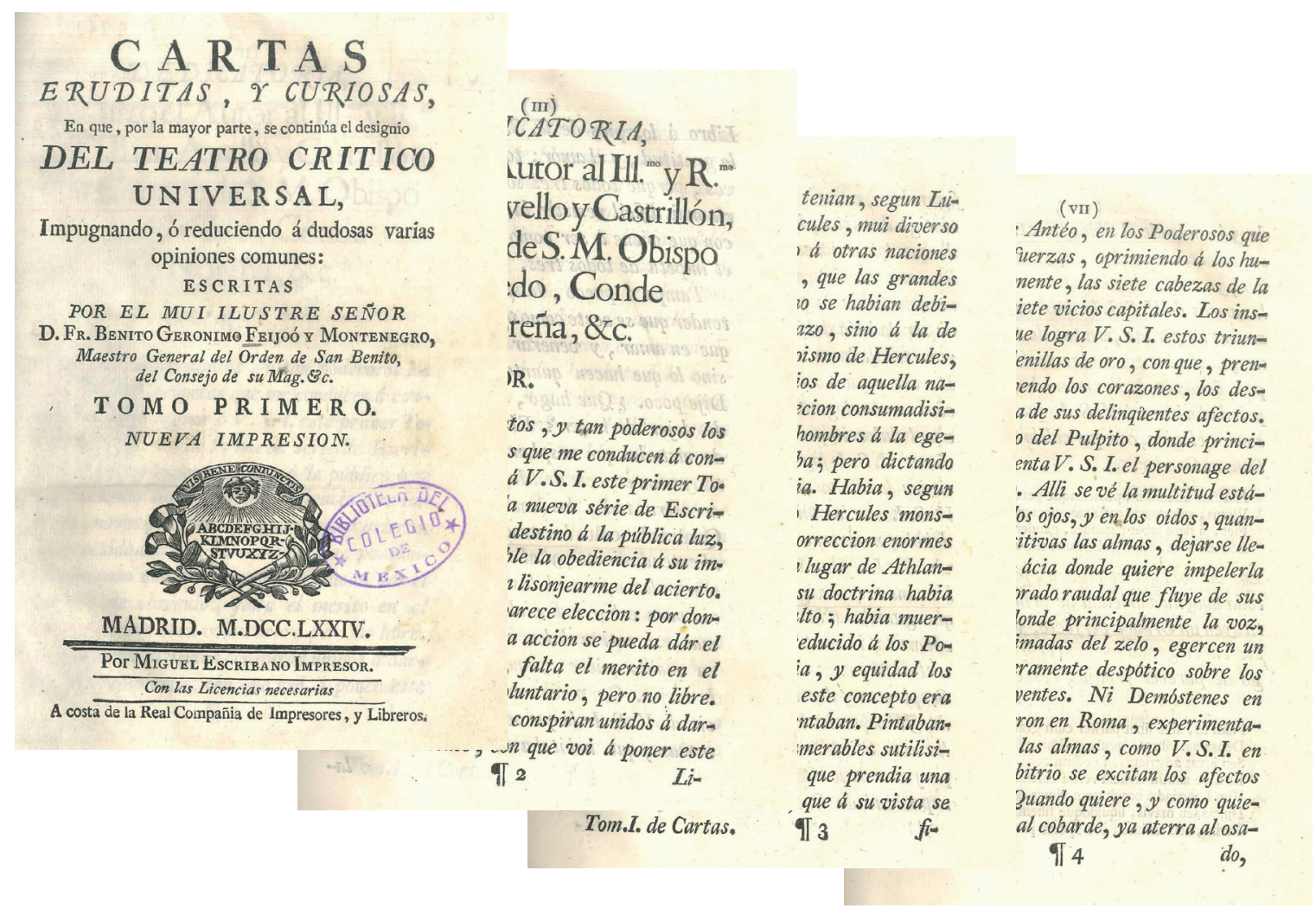

Figura 2 Indicación de la signatura del cuadernillo de preliminares. (Fuente: Feijoo, Benito Jerónimo. Cartas eruditas, y curiosas, en que, por la mayor parte, se continúa el designio del Teatro crítico universal ... Madrid: M. Escribano, 1774. v. 1)

3 José Martínez de Sousa, Diccionario de bibliología y ciencias afines, $3^{\text {a }}$ ed., Biblioteconomía y administración cultural, 34 (Gijón: Trea, 2004), 424.

\section{Número de página}

La numeración de páginas tiene su antecedente en la foliación de las hojas, es decir, colocar un número en la página impar (recto) de cada una y dejar el reverso (verso) en blanco. Dicha práctica se observa en varios incunables y otros impresos al comienzo del siglo XVI. Parece ser que la práctica de numerar las páginas de una obra, es decir, colocar un número consecutivo en el recto y el verso de la hoja, se ve por primera vez en la Cornucopiae de Nicolo Perotti, impresa en 1499, en los talleres venecianos de Aldo Manucio. ${ }^{3}$ En la actualidad, lo más común es que los impresos estén paginados con números romanos para las preliminares y con arábigos para el contenido o texto de las obras.

\section{Volumen, tomo y parte}

Es relativamente común encontrar obras en varios volúmenes o divididas en tomos, inclusive, fraccionadas en partes; dichas posibilidades tienen que ver con la extensión y el contenido de las 
4 Domingo Buonocore, Diccionario de bibliotecología: términos relativos a la bibliología, bibliografía, bibliofilia, biblioteconomía, archivología, documentología, tipografía y materias afines. $2^{a}$ ed. aum. (Buenos Aires: Marymar, 1986), 204.

5 Ibid., 198.

6 La nota aparece en la cubierta de la Historia de la Revolución Mexicana, publicada por El Colegio de México y se acompaña del título de cada uno de los 23 tomos. mismas. El primer caso implica "una divisón material que depende sólo de la forma de la encuadernación o del impresor" "es decir, responde a la necesidad de hacer más facil de manejar un contenido que resulta muy extenso para publicarse en una sola pieza. Es común que los diccionarios y enciclopedias tengan dicha característica, además, generalmente las páginas del contenido presentan una sucesión que compende la totalidad de los volúmenes de la obra.

Por otra parte, un tomo es la "unidad racional o ideológica que hace el propio autor de la Obra y significa una parte o porción del contenido o materia de la obra misma". ${ }^{5}$ En general, cada uno de los tomos tiene páginación independiente y suelen encuadernarse de manera separada, aunque, algunas veces, si el contenido es breve, pueden agruparse dos o tres tomos en un solo volumen. Valga de muestra la siguiente nota:

Para beneficio del lector, esta Historia de la Revolución Mexicana ha sido repartida en 23 tomos de poco bulto y bien ilustrados, a razón de dos, tres y hasta cuatro por periódo histórico. Cada tomo constituye una monografía y simultáneamente un eslabón de la cadena de $23{ }^{6}$

Respecto del hecho de encontrar el contenido de una obra dividido en partes, debe considerarse que generalmente tiene que ver con la extensión del contenido, se suele dividirlo y consignar con precisión el número de parte correspondiente para facilitar su manejo.

\section{Precio}

Las menciones sobre el precio de un impreso que aparecen en el mismo, obedecen, en general, a las siguientes circunstancias: 1) cumplir con preceptos legales y 2) promover y publicitar publicaciones con fines comerciales.

En el caso español, la legislación sobre publicación de impresos se remonta al siglo XVI, con la emisión de una pragmática de los Reyes Católicos de 1502, que se complementa con otra de Carlos I de 1554 y una más de Felipe II fechada en 1558, a las que sigue una renovación de validez, de mano de Felipe IV en 1627.

De manera sucinta, la posibilidad de imprimir un libro implicaba el siguiente proceso: El individuo que quisiera dar a las prensas una obra, solicitaba una licencia de impresión al Consejo Real (de Aragón, Castilla, Portugal, Indias, Italia o Flandes). Acompañaba la petición del manuscrito, que sería firmado por un escribano en todas sus hojas y pasaría a un censor para que emitiera un informe, en caso de que fuera negativo, el manuscrito sería retenido y la licencia negada; si resultaba favorable, el informe constituiría una Aprobación. Con dicha Aprobación, el Consejo emitiría la licencia y devolvería al solicitante el manuscrito, junto con la aprobación y la licencia. Se procedería a la impresión de la obra, al concluir dicha tarea, un ejemplar se entregaría al Consejo con el manuscrito original rubricado. Un corrector verificaría que la impresión se correspondiera con el manuscrito y 
emitiría una fe de erratas. Ya con la fe de erratas, el Consejo daría una certificación de tasa, en la Que se indicaba el precio al que debería venderse el libro sin encuadernar. Cabe mencionar que los cuatro documentos mencionados - aprobación, licencia, tasa y fe de erratas (figura 3), - formarían parte del cuadernillo de preliminares del texto impreso mismo que se daba a las prensas en último lugar (figura 4). ${ }^{7}$
FEE DE ERRATAS.

Carta XCIII. Pag. 32 5. lin. 17. fi fon, lee fino fon. Y corregida efta errata correfponde al impreffo, que rubricado firve de original. Madrid 19. de Oftubre de 1752.

Lic. D. Manuel Licardo de Rivera, Corrector General por S. M.

Taffaron los Señores del Real Confejo efte Tomo II. de las Cartas de Santa Terefa de Jefus à doce maravedis cada pliego, como mas largamente confta de la Certificacion original. Madrid 24. de Octubre de 1752.

\section{Donfoleph Antonio de Yarza.}

Figura 3 Fe de erratas y tasa, (Fuente: Cartas de Santa Teresa de Jesús, madre y fundadora... Madrid: Joseph de Orga, 1752. v. 2)

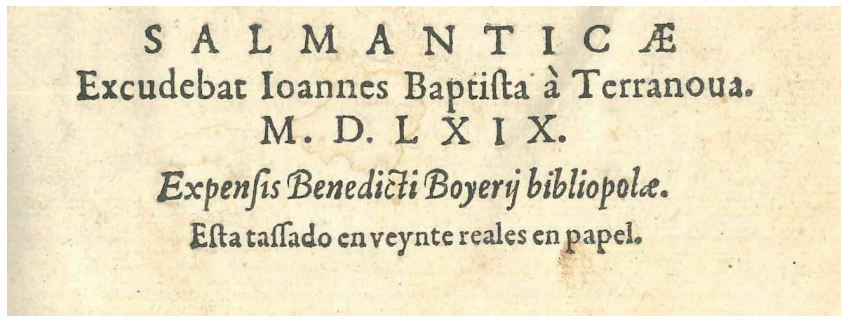

Figura 4 Mención de lugar de impresión, impresor y tasa. (Fuente: Soto, Domingo de, fray. Fratris Dominici Soto Segoviencis... de iustitia [et] lure libre decem.... Salmanticae: Excudebat Ioannes Baptista à Terranoua, 1569.)

Respecto a la promoción de publicaciones, en algunos impresos se hace referencia a otros títulos del mismo autor disponibles para su venta (figura 5). En la actualidad, los libros generalmente no llevan impreso el precio al que se venden. 


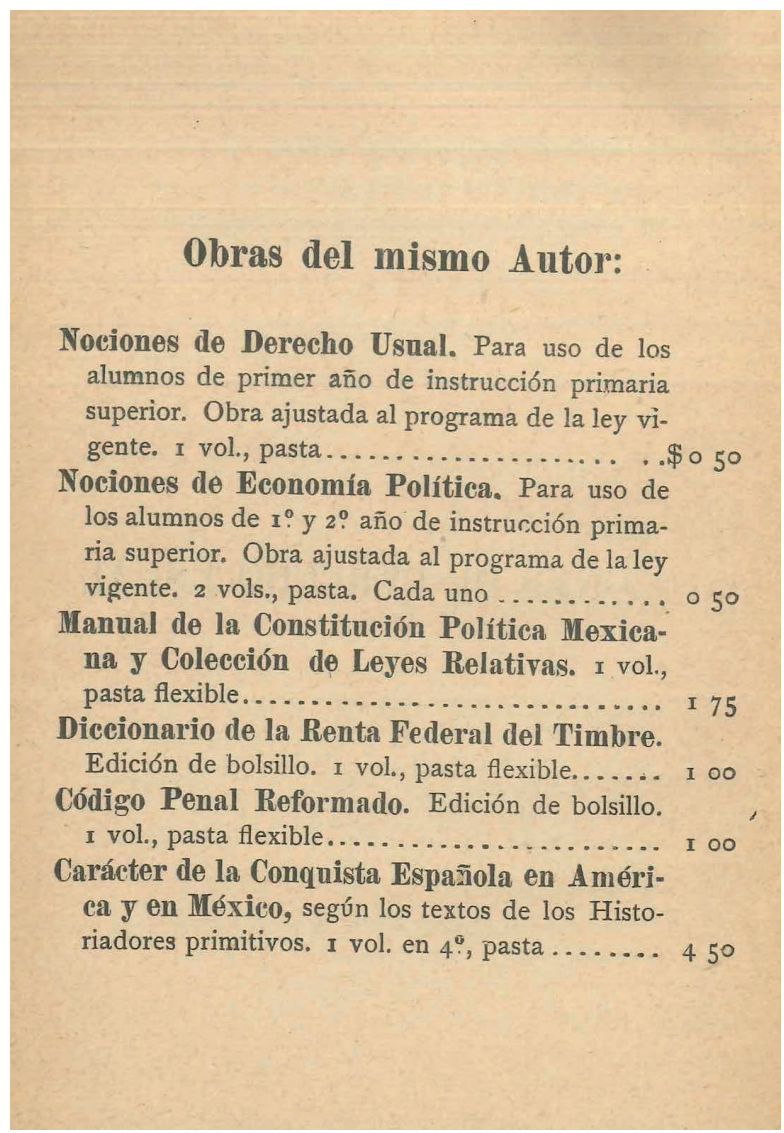

Figura 5 Obras disponibles en venta con indicación de precio (Fuente: García, Genaro. Nociones de derecho usual. $3^{\mathrm{a}}$ ed. Mexico: Librería de la Viuda de Ch. Bouret, 1901.)

\section{Número de edición}

La indicación de ediciones sucesivas de una obra, significa que el texto originalmente editado se ha modificado con el propósito de publicar una nueva edición. Al respecto, es posible identificar las siguientes categorías:

1. Edición: conjunto de ejemplares impresos de una vez con un mismo molde. Si se trata de la primera edición, ésta se denomina edición original o primera edición.

2. Edición revisada o corregida: se trata de una nueva edición de una obra publicada previamente cuyo texto es corregido por su autor o por otra persona a quien se delega la responsabilidad. Generalmente se incluye el número de edición de que se trata (figura 6).

3. Reedición: nueva edición de una obra que presenta modificaciones en su presentación, es decir, no incluye modificaciones textuales, únicamente cambios materiales (formato, tipo y tamaño de letra, etc.).

4. Reimpresión o nueva tirada: impresión de una obra con el 

nueva edición, aunque se corrijan en ella las erratas de la anterior. ${ }^{8}$

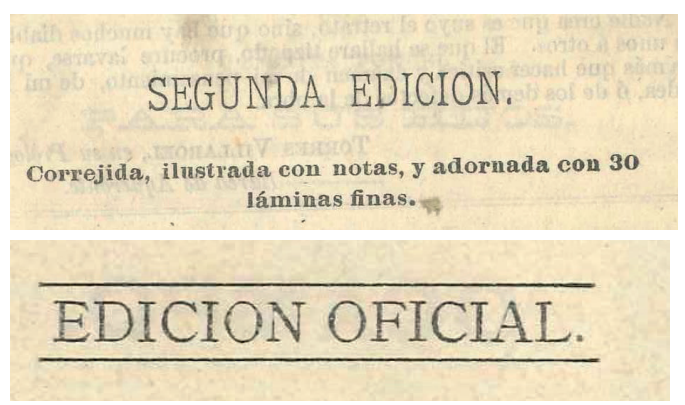

Figura 6 Menciones de edición con información adicional. (Fuentes: Fernández De Lizardi, Jose Joaquín. El periquillo sarniento. $2^{\mathrm{a}}$ ed. Mexico: J. Valdés y Cueva, 1885. Código de procedimientos civiles del Estado de Michoacán de Ocampo. Morelia: Escuela Industrial Militar

Por lo general, la mención de la primera edición aparece indicada únicamente en la página legal o de derechos, se acompaña del año y en ocasiones del mes en que se publicó. En algunos casos se consigna otra información sobre características de la edición, por ejemplo: $1^{\mathrm{a}}$ edición, 2000; Primera edición: diciembre de 1999 o Primera edición en español, 1970.

A partir de la segunda edición la información se ordena cronológicamente y se acompaña de datos relevantes respecto de la obra.

1a edición, 1974

$2^{2}$ edición, 1981

Primera edición 1996

Segunda edición, corregida y aumentada, 2009

Segunda edición, 2000

Primera edición 1995

Primera edición (2000 ejemplares), 1966-1967

Segunda edición (2000 ejemplares), 1970

Primera reimpresión corregida (2000 ejemplares), 1971

Segunda reimpresión (3000 ejemplares), 1972

Tercera reimpresión (5000 ejemplares), 1973

Cuarta reimpresión (10000 ejemplares), 1974

Quinta reimpresión (20000 ejemplares), 1976

Sexta reimpresión (20000 ejemplares), 1978

Séptima reimpresión (20000 ejemplares), 1979

Tercera edición (100000 ejemplares), 1981

Cuarta edición (25000 ejemplares), 1988, en coedición con Editorial

Harla, S.A. de C.V. 


\section{Número de ejemplar}

9 José Martínez de Sousa, Diccionario de tipografía y del libro, $2^{\underline{a}}$ ed. (Madrid: Paraninfo, 1981), 90.
Se define así la "unidad de tirada, o sea, cada una de las copias impresas de que consta una edición”. ${ }^{9}$ Si después de concluida la edición se utilizan los mismos moldes para imprimir otro conjunto de ejemplares, se trata de una reimpresión o una nueva tirada.

Las menciones sobre el número de ejemplares de que consta una edición generalmente se indican en la parte final del texto.

La edición consta de 2000 ejemplares

Tiraje: 700 ejemplares

El tiraje fue de 1000 ejemplares

Tiro: 3000 ejemplares, más sobrantes para reposición

En algunos casos, además de la edición completa, se hacen tiradas con un número reducido de ejemplares, con características especiales que aumentan su valor (figura 7 y 8 ).

Tirada aparte de cincuenta ejemplares numerados.

$$
\text { Ej. n. }{ }^{\circ} \quad 9
$$

Figura 7 Indicación de ejemplar numerado de una tirada especial. (Fuente: Paz, Octavio. Presente. Madrid : Palma de Mallorca: Papeles de son armadans, 1965.)

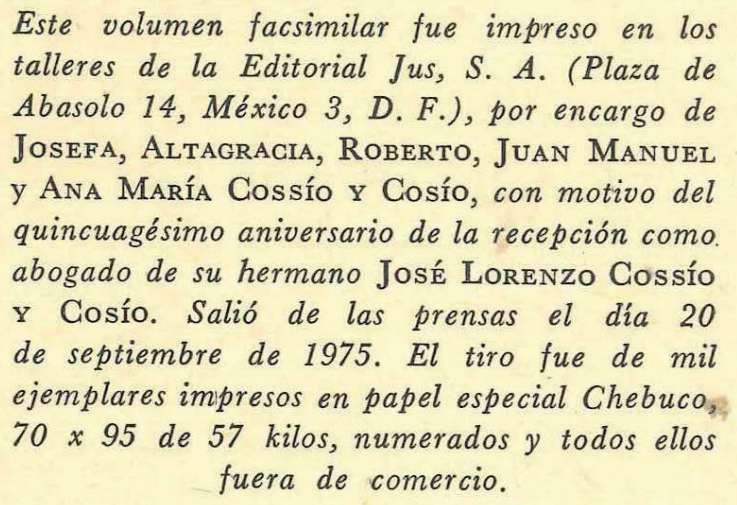

Figura 8 Edición numerada y fuera de comercio. (Fuente: Abad y Aramburu, Julián. Oración fúnebre ... por la alma de el señor Don Josef Escandón y Helguera ... Ed. facsimilar. Mexico: Jus, 1975.) 


\section{Número de serie y colección}

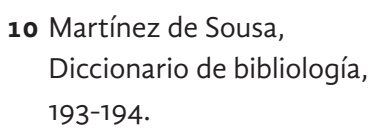

11 Buonocore, 133.

12 Martínez de Sousa, Diccionario de bibliología, 194.

13 Esfuerzo conjunto con el Fondo de Cultura. Al respecto véase el texto publicado en la Introducción de La Casa de España y El Colegio de México: catálogo histórico, 12-16.

14 Librería Porrúa. "Historia," https://www.porrua. $\mathrm{mx} /$ (consultado el 5 de septiembre, 2013).

15 Martínez de Sousa, Diccionario de bibliología, 195.
Se entiende por colección al conjunto de obras independientes, reunidas por características similares internas (temática, época, autores) y externas (formato, tipografía, diseño), con numeración o sin ella, con un título colectivo común además del título propio de cada una de ellas. Bibliológicamente, la palabra propia es serie, pero editorialmente es colección; en el mismo sentido editorial, la serie se usa como una subdivisión dentro de una colección, pero en bibliología se denomina subserie. De acuerdo con lo anterior, en la práctica su usan de manera distinta, aunque algunas ocasiones parezcan sinónimos. ${ }^{10}$ Por su parte, Buonocore considera que una "colección presupone una idea selectiva y ordenadora, esto es, un conjunto bibliográfico armonioso y homogéneo que responde a un criterio dado. Ese sentido auténtico de colección, ha sido desnaturalizado [...] aplicándose el término a cualquier grupo heteróclito de libros". ${ }^{11}$

Las primeras colecciones salieron de los talleres de Aldo Manuzio, quien imprimió una colección de clásicos de bolsillo a principios del siglo XVI, a la que siguieron las de otros impresores como los Elzevir. La época moderna de las colecciones se inicia en la Francia del siglo XVIII con el librero Gervais Charpentier, editor de una serie de cuatrocientos títulos de autores clásicos y contemporáneos. ${ }^{12}$

En el caso de México, durante el siglo XX fueron varias las casas editoriales que emprendieron amplias colecciones bibliográficas. Entre las publicadas por el Fondo de Cultura Económica baste mencionar: Biblioteca americana, Breviarios, Colección popular y Letras mexicanas. La Universidad Nacional Autónoma de México, editó, entre muchas otras: Cuadernos de poesía, Biblioteca de letras, Nuestros clásicos, Lecturas jurídicas y Opúsculos. Por su parte, de El Colegio de México destacan Tezontle ${ }^{13}$ y Jornadas. La editorial Porrúa publicó una de las colecciones más conocidas en el país por su uso para la educación básica, en 1959, apareció “Sepan Cuántos...”, bautizada así por Alfonso Reyes, colección dedicada a las obras clásicas de todos los tiempos, bajo el precepto: "la cultura al alcance de todos". ${ }^{14}$

Existen diversos tipos de colecciones, aquellas cuyo número de títulos ha sido fijado de antemano, se denominan Colección cerrada; por el contrario, en una Colección abierta no está previsto el número final. ${ }^{15}$

\section{Sistema Internacional de Numeración de Libros (ISBN)}

En la Tercera Conferencia Internacional sobre Investigación y Racionalización del Mercado del Libro, que se realizó en Berlín durante el mes de noviembre de 1966, se consideró la necesidad de contar con un sistema numérico internacional para la identificación de libros. Entre sus características, dichos números deberían tener una estructura sencilla y ser únicos para cada publicación. 
16 Manual del usuario del ISBN, 6ae ed. en español (Londres: Agencia Internacional del ISBN, 2012), 5 .

17 lbid., 6

18 Para mayor información sobre el Instituto Nacional del Derecho de Autor consulte: http://www. indautor.gob.mx/
El sistema desarrollado se denominó Sistema Internacional de Numeración de Libros (International Standard Book Number - ISBN) y retomó el método propuesto por J. Whitaker \& Sons Ltd. en el Reino Unido (1967), y por la compañía R. R. Bowker en Estados Unidos (1968).

Por su parte, el Comité Técnico 46 de la Organización Internacional de Normalización (ISO), estudió la posibilidad de adaptar la propuesta inglesa para aplicarla de manera internacional. Como resultado de varias reuniones celebradas durante 1968 y 1969, se aprobó el ISBN como norma ISO 2108 en 1970.

El objetivo de la norma internacional es coordinar y normalizar a nivel internacional la utilización de los ISBN para identificar de manera inequívoca una publicación, o una edición de una publicación, editada por un determinado editor en un determinado formato. ${ }^{16}$

Entre las ventajas del uso del ISBN se encuentran:

- Es un identificador internacional único para publicaciones monográficas

- Permite diferenciar distintos formatos y ediciones de un libro (impreso o digital)

- Facilita la compilación y actualización de directorios y bases de datos sobre el comercio del libro (como catálogos de libros a la venta)

- La solicitud y distribución de libros se hacen principalmente por medio del ISBN

- En catálogos automatizados de bibliotecas, librerías y proveedores de libros, la búsqueda de títulos por ISBN resulta rápida y eficaz

El ISBN se estableció en México en diciembre de 1977. Actualmente el Instituto Nacional del Derecho de Autor ${ }^{18}$ funge como Agencia Mexicana ISBN encargada de gestionar el ISBN en nuestro país.

\section{Estructura del ISBN}

La norma es utilizada actualmente en 160 países y ha sufrido modificaciones acorde con la aparición de nuevos formatos y soportes de información. En 2001 se constituyó un grupo de trabajo para revisarla y redactar su cuarta edición. En aquel momento, se propuso modificar la extensión del ISBN que pasaría de 10 a 13 dígitos a fin de aumentar la capacidad del sistema. En atención a lo anterior, a partir del 1 de enero de 2007 todos los números de ISBN constan de 13 dígitos, que se estructuran en cinco elementos (Tabla 2). 
19 GS1 es una organización internacional sin fines de lucro con presencia en más de 100 países dedicada al diseño e implementación de estándares. Para mayor información consulte: http://www.gs1.org

\begin{tabular}{|c|c|}
\hline $\begin{array}{l}\text { 1. Elemento prefijo (longitud fija). Se compone de } 3 \text { dígi- } \\
\text { tos, a partir de un standard establecido por la organiza- } \\
\text { ción GS1 }{ }^{19} \text {. Hasta el momento, los prefijos definidos son } \\
978 \text { y } 979 \text {. }\end{array}$ & 978 \\
\hline $\begin{array}{l}\text { 2. Elemento de grupo de registro (longitud variable). Per- } \\
\text { mite identificar un país, un área geográfica o lingüística. } \\
\text { Puede constar de hasta } 5 \text { dígitos. A México le correspon- } \\
\text { den los prefijos: } 970,968 \text { y } 607 \text {. }\end{array}$ & $978-607$ \\
\hline $\begin{array}{l}\text { 3. Elemento del titular (longitud variable). Identifica a un } \\
\text { editor o sello editorial. La extensión del mismo se define } \\
\text { en razón de la previsión del número de publicaciones, a } \\
\text { mayor número de publicaciones probables el identifica- } \\
\text { dor tiene menos dígitos. Puede constar de hasta } 7 \text { dígitos. } \\
\text { Por ejemplo, las publicaciones de El Colegio de México } \\
\text { se identifican con el prefijo } 462 \text {, las del Fondo de Cultura } \\
\text { Económica con } 16 \text { y con el } 02 \text { las editadas por la Universi- } \\
\text { dad Nacional Autónoma de México. }\end{array}$ & $978-607-462$ \\
\hline $\begin{array}{l}\text { 4. Elemento de publicación (longitud variable). Posibilita } \\
\text { la identificación de una publicación específica y una edi- } \\
\text { ción concreta. Su extensión puede tener hasta } 6 \text { dígitos. }\end{array}$ & $978-607-462-369$ \\
\hline $\begin{array}{l}\text { 5. Dígito de control (longitud fija). Se integra por } 1 \text { digito } \\
\text { y permite validar el resto del número, se calcula a partir } \\
\text { de un algoritmo. }\end{array}$ & $978-607-462-369-7$ \\
\hline
\end{tabular}

Tabla 2 Elementos del ISBN

\section{Indicaciones sobre el uso del ISBN}

Entre las principales indicaciones para el uso de números ISBN se encuentran:

Corresponderá un ISBN distinto a cada publicación monográfica, a cada una de sus ediciones y a cada uno de los formatos en que se publique.

ISBN 968-12-0704-1 ( $1^{\mathrm{a}}$ edición, 1996)

ISBN 978-607-462-012-2 (2a edición, 2009)

Se debe asignar un ISBN diferente si:

Se hacen cambios significativos en una o varias partes de una publicación

Si se han hecho cambios en el título o el subtítulo de una publicación

Si se hace una reimpresión facsimilar cuando es publicada por otro editor, o por el mismo con otro sello editorial

Una publicación tiene diferentes formatos (encuadernación en tela, rústica, edición electrónica)

Una publicación consta de más de un volumen, deberá asignarse un ISBN para toda la obra y uno a cada volumen.

ISBN 978-607-462-289-8 (obra completa)

ISBN 978-607-462-290-4 (volumen I) 
20 Además de las indicaciones mencionadas, pueden consultarse otras en la página de la Agencia Internacional ISBN, "ISBN FAQ. Ámbito de aplicación del ISBN", disponible en: http://www.isbninternational.org/faqs
ISBN 978-607-462-291-1 (volumen II)

ISBN 978-607-462-292-8 (volumen III)

ISBN 978-607-462-293-5 (volumen IV)

Si se trata de una coedición, cada uno de los coeditores deberá asignarle su ISBN y todos aparecerán en la página legal.

ISBN 978-607-462-375-8 (El Colegio de México)

ISBN 978-607-02-3106-3 (UNAM. Instituto de Investigaciones Sociales)

Ningún número de ISBN asignado podrá ser reutilizado en otra publicación monográfica, inclusive si se hubiera asignado de manera equivocada.

El ISBN debe colocarse en la página legal de los libros (también denominada de derechos) o al pie de la página del título. Si el libro no cuenta con un código de barras, también se coloca en la tapa o cubierta, preferentemente en la parte inferior derecha, de lo contrario, el código de barras se coloca en dicha posición (Figura 9). Para el caso de publicaciones electrónicas, el ISBN deberá aparecer en la pantalla del título o la del copyright, antes de iniciar con la publicación. Para otros soportes, el ISBN se colocará en las etiquetas de estos, en caso de no ser posible, se imprimirá en la parte inferior trasera de la caja o funda del soporte. ${ }^{20}$

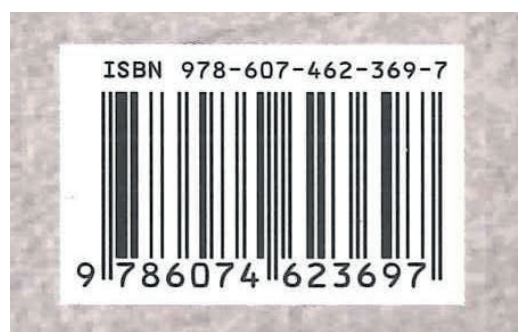

Figura 9 ISBN y código de barras de un libro. (Fuente: Práctica y fracaso del primer federalismo mexicano, 1824-1835 / Josefina Zoraida Vázquez y José Antonio Serrano Ortega, coordinadores. México, D.F.: El Colegio de México, Centro de Estudios Históricos, 2012.)

\section{Sistema Internacional Normalizado de Series (ISSN)}

De manera análoga al caso de los libros, se tiene el Sistema Internacional Normalizado de Series, para las publicaciones seriadas, es decir, aquellas que aparecen en una sucesión de fascículos, generalmente numerados u ordenados cronológicamente y sobre los cuales no se tiene una fecha prevista de culminación.

El Sistema Internacional Normalizado de Series (International Standard Serial Number - ISSN) se desarrolló en 1971 por la Organización Internacional de Normalización (ISO) con el propósito de satisfacer la necesidad de un código de identificación breve, único e 
21 Para mayor información sobre el sistema ISSN se puede consultar el ISSN Manual, disponible en: http://www.issn.org/files/ issn/Documentation/ Manuels/ISSNManual2012GBR.pdf

22 Los datos proceden del sitio ISSN International Centre, The ISSN Register, disponible en: http://www. issn.org/2-22639-TheISSN-Register.php

23 Martínez de Sousa, Diccionario de bibliología, 525 . inequívoco para publicaciones seriadas. ${ }^{21}$

El ISSN facilita la identificación de cualquier publicación seriada, incluyendo las electrónicas, independientemente del país de publicación, idioma, alfabeto, frecuencia, o medio. Los números ISSN se componen de dos series de cuatro dígitos separados por un guión, precedidos de la sigla ISSN.

Entre las ventajas del uso del ISSN se tienen:

- Posibilita la identificación precisa de los títulos de las publicaciones seriadas

- En las bibliotecas facilita el control y organización de los registros de las publicaciones seriadas, el reclamo de fascículos, la integración de catálogos colectivos, etc.

- Facilita el intercambio de información entre editores y proveedores de publicaciones periódicas, en beneficio de la distribución y comercialización de ellas ${ }^{22}$

La asignación del ISSN a una publicación seriada se vincula directamente a su título registrado de manera normalizada, que se denomina título clave y está controlado por el International Serials Data System (ISDS) con sede en París. Cada título clave se asocia a un ISSN y a una publicación específica, por lo tanto, si una publicación seriada cambia de título, deberá asignársele un nuevo título clave y un ISSN distinto.

En los fascículos, el ISSN debe imprimirse en la parte superior derecha con las siglas ISSN seguidas de los dos bloques de cuatro dígitos separados por el guión, para el caso de series monográficas, que también tienen ISBN, ambos números se colocan en la página legal o de derechos, cada uno precedido de la sigla correspondiente. ${ }^{23}$

ISBN 978-80-246-1963-7

ISSN 0536-2520

ISSN y código de barras

Con propósito comercial y basado en el código EAN13, es posible representar el ISSN como código de barras (figura 10). El sistema también es gestionado por la organización GS1 en acuerdo con el Centro Internacional ISSN y se estructuran con 4 elementos (tabla 3). 
24 Mayor información sobre los códigos de barras está disponible en: http://www. issn.org/2-22642--ISSNand-barcoding.php

\begin{tabular}{|c|c|}
\hline $\begin{array}{l}\text { 1. Elemento prefijo (longitud fija). Se compone de } 3 \\
\text { dígitos, a partir del standard establecido por la organi- } \\
\text { zación GS1. El prefijo definido para la venta de publi- } \\
\text { caciones seriadas es } 977 \text {. }\end{array}$ & 977 \\
\hline $\begin{array}{l}\text { 2. Elemento ISSN (longitud fija). Se compone de los } \\
\text { siete primeros dígitos del ISSN (sin el guión y omitien- } \\
\text { do el dígito de control). }\end{array}$ & 9771794111 \\
\hline $\begin{array}{l}\text { 3. Elemento de información adicional (longitud fija). } \\
\text { Corresponde a los dígitos } 11 \text { y } 12 \text {, reservados para } \\
\text { expresar información adicional asignada por el editor. } \\
\text { Normalmente, esto es para indicar un cambio de pre- } \\
\text { cio. Su valor por defecto suele ser } 00 \text { (cero cero). }\end{array}$ & 977179411100 \\
\hline $\begin{array}{l}\text { 4. Dígito de control (longitud fija). Se integra por } 1 \text { digito } \\
\text { y permite validar el resto del número, se calcula a partir } \\
\text { de un algoritmo. Es probable que el dígito de control del } \\
\text { código de barras sea diferente al del ISSN. }{ }^{24}\end{array}$ & 9771794111005 \\
\hline
\end{tabular}

Tabla 3 Elementos de código de barras para ISSN

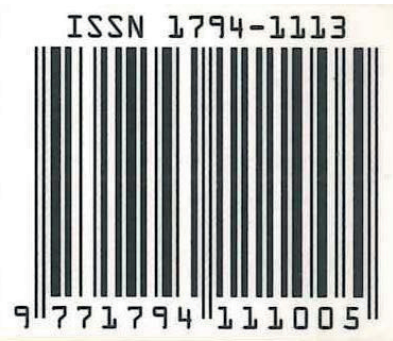

Figura 10 Código de barras de publicación seriada con el ISSN correspondiente. (Fuente: Odeon : observatorio de economía y operaciones numéricas. Bogotá: Universidad Externado de Colombia, Facultad de Finanzas, Gobierno y Relaciones Internacionales: Centro de Investigaciones y Proyectos Especiales, 2003-)

\section{Número de Depósito Legal}

El Número de Depósito Legal (DL) se sustenta en la entrega obligatoria y gratuita a un archivo o biblioteca pública, de uno o más ejemplares de cualquier publicación impresa de un país determinado, conforme a las disposiciones legales del mismo.

Su origen se da en Francia con Francisco I (1538) quien ordena al editor Robert Estienne entregar a la Biblioteca Real un ejemplar de cada libro griego que imprima. Para 1662 Inglaterra emite su "Licensing act", donde obliga a los editores a entregar tres ejemplares a la Biblioteca Bodleyana, en la Universidad de Oxford. En España, se tiene un antecedente durante el reinado de Felipe IV, quien concede un privilegio a la Biblioteca de El Escorial para obtener gratuitamente un ejemplar de todo libro impreso, posteriormente, con la fundación de la Biblioteca Nacional en 1712 se implantó el depósito legal. ${ }^{25}$
25 Martínez de Sousa, Diccionario de bibliología, 266. 
La obligación de cumplir el DL depende del impresor, quien debe solicitar el número que le corresponda y cuando la obra esté terminada hacer el depósito. Entre los impresos que deben depositarse se encuentran: anuncios artísticos, cromos, estampas, folletos, grabaciones sonoras, hojas impresas no publicitarias, libros, mapas y planos, partituras musicales, producciones cinematográficas y publicaciones periódicas, entre otras.

Algunos de los materiales no sujetos al depósito legal son: sellos de correo; impresos de carácter social (invitaciones), y aquellos de carácter comercial que no tengan grabados artísticos o textos técnicos o literarios. ${ }^{26}$

Generalmente se encuentra dispuesto en la página legal, precediendo al ISBN, este número consta de la sigla de la provincia o lugar de impresión, el número que le corresponda y el año de impresión (figura 11).

\section{Depósito legal: As. 481-2004 ISBN: 84-9704-082-1}

Figura 11 Número de depósito legal con el indicativo As. (Asturias) (Fuente: Martínez de Sousa, José. Diccionario de bibliología y ciencias afines: terminología relativa a archivística, artes e industrias gráficas, bibliofilia ... $3^{\mathrm{a}}$ ed. corregida y notablemente aumentada. Asturias, España: Ediciones Trea, 2004.)

\section{Digital Object Identifier (DOI)}

Se trata de un medio de identificación que asigna un código único a entidades en entornos digitales. No hace referencia a la ubicación de la entidad, lo que permite localizarla independientemente del sitio en que se encuentre.

El origen del sistema es resultado de una iniciativa de tres organizaciones relacionadas con la industria editorial (International Publishers Association; International Association of Scientific, Technical and Medical Publishers; Association of American Publishers). Aunque en un principio se asoció a la publicación de textos, el DOI se concibió como un marco para la identificación de contenidos a través de redes digitales.

La propuesta sobre el sistema se dio a conocer en la Feria del Libro de Frankfurt 1997, ese mismo año fue creada la Fundación Internacional DOI (International DOI Fundation) para desarrollar y gestionar el sistema. En 2012 fue adoptado como norma ISO 26324. 
27 Para ampliar información sobre el DOI consulte: "DOI Handbook." http://www. doi.org/hb.html
28 William Stetson Merril, Code for clasifiers, 2nd ed. (Chicago: ALA, 1939), 2.
Cada DOI está integrado por dos componentes, el prefijo y el sufijo, que juntos forman el nombre DOI, separados por el carácter “/”. El prefijo identifica a las organizaciones o titulares y el sufijo consiste en una cadena de caracteres elegida por el solicitante del registro. El sufijo puede ser un número secuencial, o incorporar datos de otros sistemas de control (ISBN, ISSN, etc.). ${ }^{27}$

Las monografías disponibles en formato electrónico, se ubican mediante su registro DOI, que generalmente incluye los datos del ISBN.

DOI10.1007/978-3-642-31196-3

ISBN 978-3-642-31195-6 Impreso

ISBN 978-3-642-31196-3 En línea

Los artículos de publicaciones periódicas disponibles en formato electrónico también pueden localizarse por su registro DOI, que incluye los datos del ISSN de la serie en línea.

DOI 10.1111/j.1467-8497.2010.01538.x

ISSN 0004-9522 Impreso

ISSN 1467-8497 En línea

\section{Números externos o de asignación posterior}

\section{Sistemas de clasificación numéricos}

Un elemento fundamental para permitir el acceso a los recursos de información dentro de una colección es la asignación de una signatura o clave construida dentro de un esquema definido, ya bien de naturaleza alfanumérica o exclusivamente con este último elemento.

Según William S. Merril "La clasificación puede ser definida como el arte de asignar a los libros un lugar exacto, en un sistema de clasificación, en el cual los distintos asuntos del saber... en sus varios aspectos están agrupados de acuerdo con su semejanza o con las relaciones de unos con otros. ${ }^{28}$ De lo anterior, se advierte que una característica fundamental en la tarea de clasificar es que está basada en el análisis del contenido de los recursos documentales. Por lo que respecta al acomodo de los documentos en un espacio físico, el uso de estos sistemas permitirá ubicar de manera cercana obras sobre el mismo tema, diferenciándose por la manera en que son abordados, por ejemplo de la generalidad a la especificidad.

Es oportuno mencionar que debe hacerse una distinción entre la clasificación como sistema ya elaborado (de Dewey, de la Biblioteca del Congreso LC, la Decimal Universal, etc.) y la clasificación como proceso intelectual, es decir, la tarea propia de asignar una clave o signatura a través del análisis del contenido temático del documento, o por un principio de organización diferente, establecido de acuerdo con las políticas de la propia colección (como puede ser el orden alfabético, por tamaño, año de publicación, orden de llegada, entre otros). "Clasificar es colocar un libro (documento, etc.) en una clase 
29 Manuel Carrión Gútiez, Manual de bibliotecas, $2^{\underline{a}}$ ed. (Madrid: Fundación Germán Sánchez Ruipérez: Pirámide, 1997), 245.

30 Ibid., 247.

31 Ver el ensayo de Héctor Vera en esta misma obra.

32 Juan Bautista Iguíniz, Léxico bibliográfico (México: UNAM: IIB, 1987), 70 . dentro de un esquema o bien agrupar los libros por características comunes y siempre $[\ldots]$ por su contenido". ${ }^{29}$

Podemos distinguir ciertos elementos básicos en todo sistema de clasificación, los cuales le dan la categoría de ser más que códigos de signos ordenados en un listado:

a) Patrón o base ideológica: Estos puntos teóricos son fundamentalmente de tres tipos:

- El filosófico: basados en la lógica aristotélica (del orden de la naturaleza), la división del conocimiento de Bacon, donde el conocimiento puede ir descendiendo dicotómicamente hasta llegar a la especie más ínfima (ejemplos de esto son la clasificación Decimal de Dewey y la Clasificación Decimal Universal)

- Visión pedagógica: la división del saber en la que se basa la enseñanza, como las teorías de Bliss

- Consideraciones prácticas: va a ser utilizado primordialmente para la ordenación física de los materiales

b) Sistema de notación: puede ser numérico, alfabético, con otros signos o mixto, la denominación (sistema alfabético o numérico) se da por la predominancia, pues ningún sistema es puro

c) Posibilidad de expresar materias compuestas: capacidad de análisis y síntesis

d) Esquema básico: clases principales y tablas que constituyan un macro-orden

e) Micro-orden o esquema desarrollado: reglas para realizar la especificación y las subdivisiones dentro de cada clase

f) Orden para archivar: hacer un lista o índice de las notaciones

g) Índice alfabético: facilitar la búsqueda de las notaciones ${ }^{30}$

En atención de los propósitos del presente documento, a continuación se hace referencia exclusivamente al sistema Decimal de Dewey, que es puramente numérico, a diferencia de LC que incluye letras y números. Actualmente el Dewey es el sistema de clasificación bibliotecaria más utilizado en el mundo, empleado en más de 135 países y traducido a más de 30 idiomas.

Clasificación Decimal de Dewey. ${ }^{31}$ Creada a fines del siglo XIX con el propósito de ordenar libros por materias, se basa en la clasificación bibliográfica de William Harris (quien había realizado una adaptación a la clasificación del conocimiento de Bacon), así como en las clasificaciones del conocimiento de Aristóteles, Locke y otros filósofos. Su creador fue el bibliotecario norteamericano Melvil Dewey (1815-1931), quien lo dio a conocer en 1876.

A fines del siglo XIX era visto como el sistema más original y práctico de los existentes hasta ese momento. ${ }^{32}$ Está basado en el sistema de numeración decimal, y divide los conocimientos en diez clases principales, con rangos de tres dígitos que van del 000-900, de la siguiente manera: 
33 El esquema abreviado está disponible en: http:// www.oclc.org/dewey/ resources/summaries. en.html

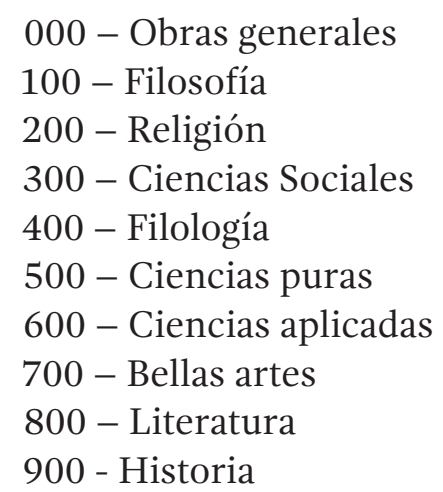

Cada una de estas clases se subdivide en diez grupos menores y así sucesiva e indefinidamente, según la extensión de la materia o el nivel de especificidad requerido en el acervo a desarrollar. El sistema basa su estructura en un modelo jerárquico decimal que comprende desde los temas más amplios a los más concretos, cada una de las diez clases principales se divide a su vez en diez divisiones y cada una de estas en diez secciones, así el nivel inferior estará subordinado al nivel superior, esto se denomina "Principio jerárquico". La jerarquía en el DDC se expresa mediante la estructura y la notación, lo cual significa que todos los tópicos (aparte de las diez clases principales) son parte de un tópico mayor superior a él.

Las clases menores tienen nueve divisiones, numeradas también del 1 al 9. Por ejemplo las divisiones del 000 Obras Generales son:

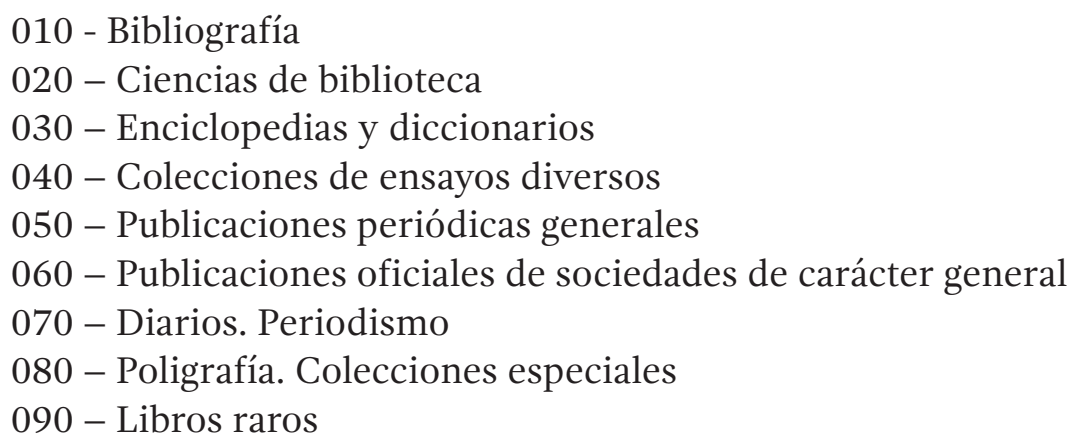

Paralelamente, a los números clasificadores se agregan determinantes comunes de forma, geográficas, idioma, etcétera, indicada cada una por su notación especial, los cuales se ubican en las Tablas del sistema que buscan mayor especificidad en la construcción de los números de clasificación. ${ }^{33}$

Fremont Rider, quien hizo un análisis al sistema de Dewey manifestó lo siguiente: "Ha habido siempre una cierta fascinación en el uso de combinaciones numéricas; así se explica que muchos supuestos expertos no se hayan dado cuenta de que el exceso de detalles en una clasificación no implica necesariamente una mejora. Debieron haber pensado que cuanto más minuciosa es, más corre el riesgo de volverse anticuada y más compleja se hace, más tiene de perder una de sus 
34 American National Biography Online, "Melvil Dewey," http://www.anb. org/articles/09/09-00229. html (consultado el 22 de agosto, 2013) mejores características: la simplicidad de su manejo. ${ }^{34}$

Desde su creación, el sistema ha sido modificado y ampliado para integrar los cambios que se han dado en las distintas disciplinas $\mathrm{y}$ se han publicado veintidós ediciones completas ( $\mathrm{y} 14$ ediciones abreviadas) hasta la fecha. En la actualidad, la Biblioteca del Congreso de Estados Unidos es la responsable del mantenimiento y actualización del esquema y sus tablas. ${ }^{35}$

\section{Número de autor o Cutter}

35 Online Dictionary for Library and Information Science, "Dewey Decimal Classification (DDC)," http://www.abc-clio. com/ODLIS/odlis_d. aspx\#dewey (consultado el 22 de agosto, 2013).

36 Iguíniz, 195.

37 Ibid, 281.

38 Disponible para su descarga en: http://www.oclc.org/ support/services/dewey/ program/license.en.html
Charles Ammi Cutter (1837-1903) fue creador del sistema de números de autor, en 1880 publicó por vez primera sus tablas de autor, para abreviar por medio de la combinación de letras y números los nombres de los autores. A partir de este número, es posible colocar los libros alfabéticamente por el apellido del autor, dentro de un mismo número de clasificación. Esa primera tabla se llamó "De dos números", sin embargo, no siempre era así, pues a veces se añadía otra letra y se usaba un número para nombres que empezaban con vocales y con la letra S, como Asturias: AsS y nombres con Sc como Scott. Kate E. Sanborn revisó estas tablas y como resultado publicó las Tablas CutterSanborn, que emplean, según el tamaño de la colección una letra y dos o tres números; con la ventaja que eso significa para distinguir nombres de similar ortografía (figura 12).

Es interesante mencionar que a principios del siglo pasado este número también era conocido como Marca del autor, el cual estaba constituido de igual manera por la letra inicial del apellido seguida de un número determinativo y puntos en distinta posición, éste combinado con el número de clasificación generaba el Número identificador. ${ }^{36}$ Juan B. Iguiniz criticó la aplicación de las Tablas de Cutter para nombres que no fueran anglosajones, pues creaban dificultades en estos casos. ${ }^{37}$ Con las nuevas tecnologías actualmente ya no es necesario el uso de las tablas de forma manual, pues existe el programa de Cutter automatizado creado por el consorcio bibliotecario internacional OCLC. ${ }^{38}$

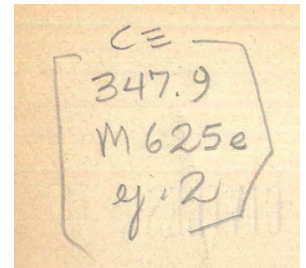

Figura 12 Anotación en el reverso de la portada en que se consigna el número de clasificación, autor y ejemplar (Fuente: Código de procedimientos civiles del Estado de Michoacán de Ocampo. Morelia: Escuela Industrial Militar Porfirio Díaz, 1895.) 


\section{Número de inventario}

También conocido como número de adquisición, o número de accesión, generalmente se trata de un número progresivo asignado a cada volumen en el orden de su ingreso a la colección y sirve para identificarlo (figuras 13 - 16). "Dicho número es intransferible, y nunca se asigna a dos o más volúmenes idénticos, aun cuando el primitivo, por alguna circunstancia haya sido sustituido por un duplicado". ${ }^{39}$ Es un número asignado a cada material documental que lo hace pertenecer a una colección en particular, es de carácter administrativo y se genera de manera consecutiva, el cual reflejara el crecimiento de una colección. Al realizar inventarios, estos números permiten cotejar las existencias físicas identificando ejemplares específicos. En la actualidad varias bibliotecas han sustituido el número de inventario por el código de barras.

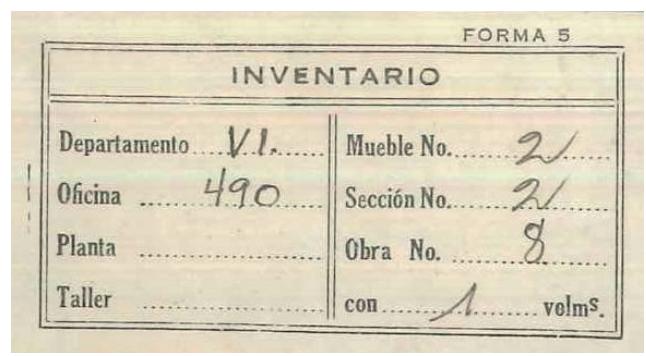

Figura 13 Etiqueta de inventario en que se consignan datos de ubicación. (Fuente: Decretos, circulares y demás disposiciones emitidas por el gobierno constitucionalista por conducto de la Secretaría de Hacienda desde abril de 1913... México: Secretaría de Hacienda, 1916.

\section{$24201 \quad 321753$}

Figura 14 Dos números de inventario consignados en un mismo documento, procedentes de dos instituciones diferentes. (Fuente: Código de procedimientos civiles del Estado de Michoacán de Ocampo. Morelia: Escuela Industrial Militar Porfirio Díaz, 1895.)

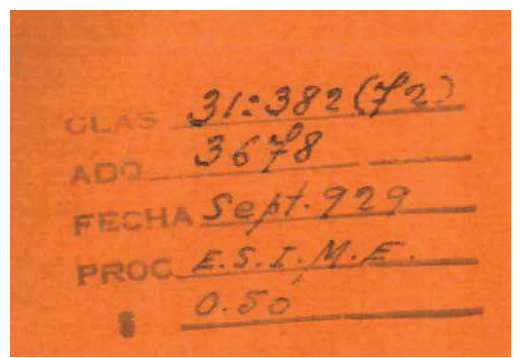

Figura 15 Sello en que se indica el número de clasificación, fecha y número de adquisición, procedencia y precio (Fuente: Importación y exportación de la República Mexicana, año de 1902. México: Secretaría de Fomento, 1903.) 


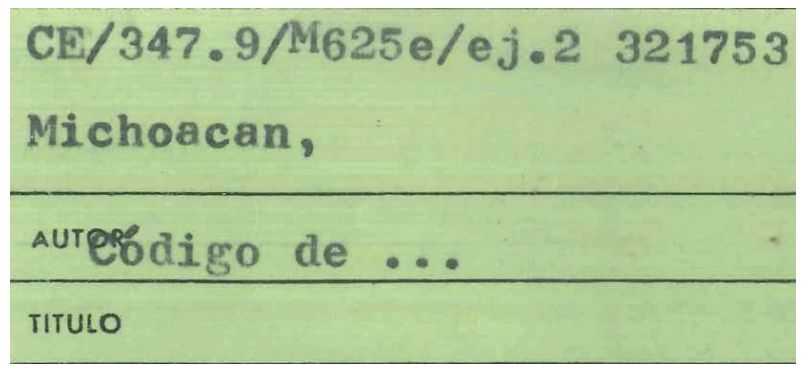

Figura 16 Tarjeta que indica clasificación, autor, ejemplar y adquisición. (Fuente: Código de procedimientos civiles del Estado de Michoacán de Ocampo. Morelia: Escuela Industrial Militar Porfirio Díaz, 1895.)

\section{Anotaciones numéricas manuscritas}

Dentro de los libros podemos encontrar infinidad de elementos que de alguna forma remiten a la pertenencia del mismo como un objeto físico, entre ellos puede haber, exlibris (en estampa o manuscrito), apostillas o anotaciones manuscritas, autógrafos, dibujos, etcétera (figuras 17 y 18). Entre las marcas que los lectores y poseedores de libros dejan en ellos, no es extraño encontrar números escritos a mano, como el precio asignado por el vendedor, un número telefónico, o códigos que sólo tienen un significado real para quien los escribió. En no pocas veces, estos vestigios ayudan a reconstruir la historia del ejemplar.

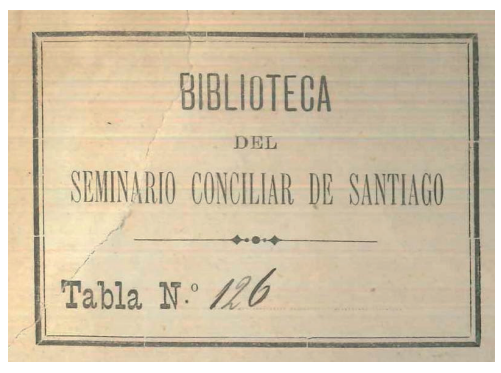

Figura 17 Etiqueta en que se indica la propiedad de la obra y su lugar en la colección. (Fuente: Morelli, Cyriaci. Fasti novi orbis et ordinationum apostolicarum ad Indias ... Venetiis: Antonium Zatta, 1776.) 


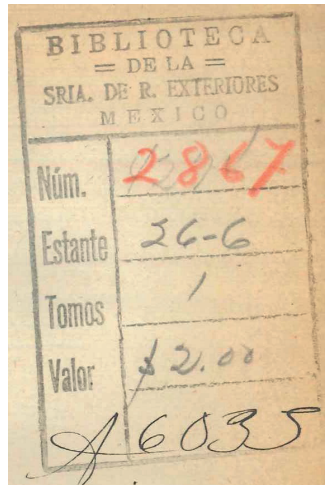

Figura 18 Sello en el que se identifica el número de adquisición, la ubicación, el número de volúmenes y el precio del impreso. (Fuente: Código de procedimientos civiles del Estado de Michoacán de Ocampo. Morelia: Escuela Industrial Militar Porfirio Díaz, 1895.)

\section{Representación del libro mediante códigos numéricos}

\section{Número en repertorios bibliográficos}

Su propósito es permitir la identificación de una referencia o noticia bibliográfica dentro del repertorio bibliográfico o bibliografía. Como es bien sabido, nuestro país cuenta con una larga historia del libro, es natural que lo mismo suceda en el desarrollo de la bibliografía mexicana (entendida como el conocimiento y descripción de los libros). Una bibliografía es un catálogo descriptivo y clasificado de las obras que han sido publicadas en un período, en un lugar o sobre una materia o por un autor determinado, lo cual delimita la naturaleza del listado. ${ }^{40}$

Existen múltiples tipos de repertorios: la Bibliografía acumulativa, la Bibliografía comercial, la Bibliografía corriente, la Bibliografía crítica, la Bibliografía de bibliografías, la Bibliografía exhaustiva, la Bibliografía general, la Bibliografía selectiva, la Bibliografía Universal, y la Bibliografía nacional, entre muchas otras (figura 19). 
316

BIBLIOGRAFIA MEXICANA DEL SIGLO XVI

$[1583$

\section{3}

102 (89). FORMA||BREVIS, ADMINI-||strandi apud Indos Sanctum||Baptismi Sacramentum: iuxta||ordinem Sanctæ Romanæ Ecclesiæ:||ex concessione. S. D. Pauli Papæ. III.||nuper summa cura, \& diligentia lima||ta, ac prælo mandata, per Fratrem||Michælem à çarate, Minoritam.: ${ }^{1}$

Un pequeñísimo grabado de la impresión de las llagas de S. Francisco.

MEXICI.||Excudebat Petrus Ocharte.||M.D.LXXXIII.

En $8^{\circ}$ menor, casi $16^{\circ}$, letra romana, rúbricas encarnadas, $72 \mathrm{ff}$. [13 líneas por $p$. Reclamos. -Signs.: A-I de 8 hojas.] En la vuelta de la penúltima se repite:

"MEXICI.||Apud Petrum Ocharte.||Typographum.||M.D.Lxxxiij.||Mense Maio."

La última hoja está ocupada con el índice.

(En mi poder. ${ }^{2}$ )

[Medina, IM, I, pp. 264-268, con facs. de la port.-Streit, núm. 142, pp. 62-63.-Wagner, Nueva bibliografía, núm. 89 , pp. 358-359, con reprod. de la port.]

Figura 19 Registro de un impreso mexicano del siglo XVI, al final se incluyen los números en que se registra la misma obra en otros repertorios bibliográficos. (Fuente: García Icazbalceta, Joaquín. Bibliografía Mexicana del siglo XVI. Nueva edición por Agustín Millares Carlo. México: Fondo de Cultura Económica, 1954.)

Debe hacerse un paréntesis para mencionar que las Bibliotecas Nacionales de Alemania, Finlandia, Noruega y Suecia asignan un número identificador denominado, Número de la Bibliografía Nacional $(N B N)$. No existen un estándar mundial sobre la estructura del NBN; sin embargo, tienen un formato para especificar el país donde se imprime o edita el libro. El NBN es usado típicamente en documentos que no tienen un identificador asignado de editor (como el ISBN). Son usados con éxito para identificar recursos almacenados en bibliotecas nacionales. ${ }^{41}$

\section{Número de sistema}

Surgido con la introducción de las nuevas tecnologías dentro de las bibliotecas y centros de información o de los sistemas de gestión bibliotecaria automatizados (ILS en inglés), son una notación asignada automáticamente al momento de generar un nuevo registro bibliográfico dentro de una base de datos, es consecutivo pues refleja el crecimiento de la base de datos o catálogo, aunque no es tan confiable para esos propósitos pues algunas veces ciertos registros pueden ser eliminados o reutilizados, lo cual alteraría la numeración consecutiva (figura 20). Dentro de las tareas de organización de una unidad de información, estos números son la entrada inmediata 
42 Martínez de Sousa, Diccionario de bibliología, 191.

43 José López Yepes, ed., Diccionario enciclopédico de ciencias de la documentación (Madrid: Síntesis, 2004), 331. a la recuperación de información para hacer correcciones o actualizaciones. No resulta de gran utilidad en procesos de búsqueda y recuperación para el usuario, se trata de un número de uso interno, generalmente utilizado por la biblioteca en procesos de adquisición, gestión y organización de la información en sistemas automatizados.

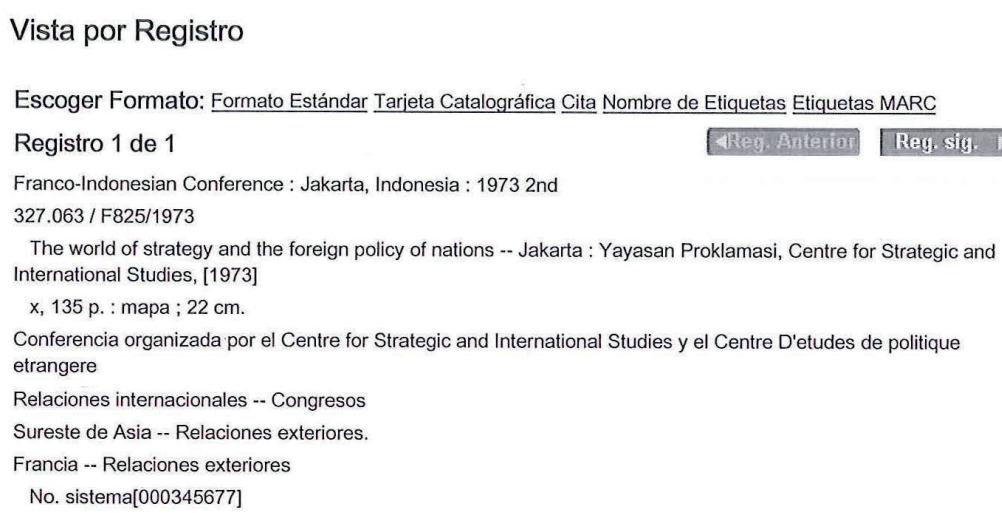

Figura 20 Despliegue de un registro bibliográfico en un sistema automatizado, donde se incluye al final el número de sistema. Biblioteca Daniel Cosío Villegas, El Colegio de México.

\section{Códigos de barras}

El sistema de codificación UPC (Universal Product Code) surge en Estados Unidos y Canadá en 1973, Europa lo adopta un año después y en 1977 se crea la EAN (European Article Numbering). Este código se basa en el sistema binario de las computadoras, las barras representan los ceros y los espacios entre ellas, los unos; las barras son de distinto grosor. Para leerlos se usa un escáner o lector óptico de caracteres, sensible a la luz, que responde de acuerdo a la luz reflejada por el blanco o el negro. Existen diversas versiones del código, denominadas de acuerdo a los caracteres que lo componen, entre ellas, EAN-13 y EAN-8, aunque la primera es la más usada. ${ }^{42}$

En bibliotecas y archivos son útiles para el control de inventarios, la adquisición, almacenamiento, circulación y control de ejemplares, incluso, sirven para identificar a sus usuarios. ${ }^{43}$

En la industria editorial se utiliza con propósitos comerciales y se coloca a cada obra desde su impresión, pues facilita un control rápido de las existencias y la obtención de estadísticas comerciales. Los códigos tienen un bajo porcentaje de error y permiten identificar rápidamente los datos de las obras y automatizar su registro.

\section{Comentario final}

Como se observa de la lectura de este trabajo, el uso de números en los libros ha tenido diversas aplicaciones a lo largo del tiempo. A 
través de este escrito pudimos definir algunas características generales en los códigos numéricos referidos que justifican su aplicación:

- Permiten identificar de manera univoca a los documentos

- Se trata de notaciones generalmente breves

- Son aplicables a colecciones documentales independientemente del tamaño de las mismas

- Pueden representar un alto grado de especificidad y de control

- Permiten organizar de manera sistemática diversos tipos de colecciones

- Posibilitan la identificación de documentos sobre una misma temática en medios electrónicos, así como su relación con otros tópicos afines

- Permiten el intercambio de información entre diversos sistemas, servicios y proveedores de información

- Ofrecen una gran capacidad de adaptación a diversos formatos, soportes y tipos de documentos

En síntesis, su utilización facilita la identificación, organización y representación de documentos, tanto en formato impreso como electrónico. Toda vez que muchos de éstos tienen una larga tradición en el mundo editorial y en el ámbito bibliotecario, podemos observar que con las nuevas tecnologías de producción y difusión de la información continúan siendo utilizados en formas novedosas y variadas.

\section{Referencias}

BUONOCORE, DOMINGO. 1986. Diccionario de bibliotecología: términos relativos a la bibliología, bibliografía, bibliofilia, biblioteconomía, archivología, documentología, tipografía y materias afines. $2^{\mathrm{a}}$ ed. aum. Buenos Aires: Marymar.

CARrión Gútiez, MANUEL. 1997. Manual de bibliotecas. $2^{\text {a }}$ ed. Madrid: Fundación Germán Sánchez Ruipérez: Pirámide.

La Casa de España y El Colegio de México : catálogo histórico, 1938-2000. México, D.F.: El Colegio de México, 2000.

Grupo de Trabajo de la IFLA sobre Directrices para las Bibliografías Nacionales 2009. Bibliografías nacionales en la era digital: Guía y nuevas orientaciones. Madrid: Biblioteca Nacional de España, disponible en:

http://www.ifla.org/files/assets/bibliography/nb_spanish_version.pdf IGUÍNIZ, JUAN BAUTISTA 1987. Léxico bibliográfico. México: UNAM: IIB.

LÓPEZ yePES, JosÉ 2004. ed. Diccionario enciclopédico de ciencias de la documentación. Madrid: Síntesis.

Manual del usuario del ISBN 2012. 6a ed. en español. Londres: Agencia Internacional del ISBN.

MARTínez DE SOUSA, José 2004. Diccionario de bibliología y ciencias afines. $3^{\mathrm{a}}$ ed. Biblioteconomía y administración cultural, 100. Gijón: Trea. 1981. Diccionario de tipografía y del libro. $2^{\mathrm{a}}$ ed. Madrid: Paraninfo,

MERRIL, WILliam STETSON 1939. Code for clasifiers. 2nd ed. Chicago: ALA. 
MONTANER FRUTOS, ALBERTo 1999. Prontuario de bibliografía: pautas para la realización de descripciones citas y repertorios. Biblioteconomía y administración cultural, 34. Gijón: Trea.

Sitios de Internet consultados

Agencia Internacional ISBN. "ISBN FAQ. Ámbito de aplicación del ISBN." http:// www.isbn-international.org/faqs (consultado el 22 de agosto, 2013).

American National Biography Online."Melvil Dewey." http://www.anb.org/articles/09/09-00229.html (consultado el 22 de agosto, 2013).

GS1. "GS1." http://www.gs1.org (consultado el 6 de septiembre, 2013).

Instituto Nacional del Derecho de Autor. "Instituto Nacional del Derecho de Autor." http://www.indautor.gob.mx/ (consultado el 6 de septiembre, 2013).

International DOI Foundation. "DOI Handbook." http://www.doi.org/hb.html (consultado el 19 de agosto, 2013).

ISSN International Centre. "ISSN and barcoding." http://www.issn.org/222642--ISSN-and-barcoding.php (consultado el 4 de septiembre, 2013).

ISSN International Centre. "ISSN Manual." http://www.issn.org/files/issn/Documentation/Manuels/ISSNManual2012-GBR.pdf (consultado el 4 de septiembre, 2013).

ISSN International Centre. "The ISSN Register." http://www.issn.org/222639-The-ISSN-Register.php (consultado el 4 de septiembre, 2013).

Librería Porrúa. "Historia." https://www.porrua.mx/ (consultado el 5 de septiembre, 2013).

Online Computer Library Center. "Dewey Cutter Program Download.” http:// www.oclc.org/support/services/dewey/program/license.en.html (consultado el 22 de agosto, 2013).

Online Computer Library Center. "Dewey Decimal Classification summaries." http://www.oclc.org/dewey/resources/summaries.en.html (consultado el 22 de agosto, 2013).

Online Dictionary for Library and Information Science. "Dewey Decimal Classification (DDC)." http://www.abc-clio.com/ODLIS/odlis_d.aspx\#dewey (consultado el 22 de agosto, 2013).

\section{Sobre los autores}

\section{Victor Cid Carmona}

$<$ vjcid@colmex.mx >

Maestro en Bibliotecología por la Facultad de Filosofía y Letras de la UNAM. Fue becario del Programa ENDESA de Patrimonio Cultural con Iberoamérica en la Biblioteca Nacional de España. Ha publicado trabajos en diversas publicaciones profesionales. Ha formado parte de la mesa directiva de la Asociación Mexicana de Bibliotecarios, A.C., de la cuál es miembro activo. Ha participado en diversos congresos y reuniones académicas nacionales e internacionales. Actualmente se desempeña como bibliógrafo para el Centro de Estudios Históricos 
en la Biblioteca Daniel Cosío Villegas de El Colegio de México, donde labora desde 1995 .

\section{Claudia Escobar Vallarta \\ <cescobar@colmex.mx > \\ Maestrante en Bibliotecología y Estudios de la Información en la UNAM. Personal académico de la Biblioteca Daniel Cosió Villegas desde 2008, ha impartido Talleres de Organización de la Información para catalogadores. Fue becada por Enlace para el LV Seminar on Aquisitions for Latin American Library Materials (SALALM), gracias al trabajo "El Libro y el Pueblo: su contribución al cimiento de la escuela bibliotecológica mexicana: 1922-1935". Ha publicado capítulos en varios libros es colaboradora del blog InfoTecarios sobre temáticas relacionadas con la Información y la Documentación en el ámbito latinoamericano http://www.infotecarios.com/author/ claudiaescobar/}

Artigo recebido em 01 mai. 2014, aprovado em 20 ago. 2014. 